\title{
The Building Information Modeling (BIM)-Based System Framework to Implement Circular Economy in Construction Waste Management
}

\author{
Tantri N. Handayani ${ }^{1 *}$, Kartika N. R. Putri ${ }^{1}$, Nurul A. Istiqomah ${ }^{1}$, Veerasak Likhitruangsilp ${ }^{2}$ \\ ${ }^{1}$ Department of Civil and Environmental Engineering, Universitas Gadjah Mada, Yogyakarta, INDONESIA \\ Jalan Grafika No 2 Yogyakarta \\ ${ }^{2}$ Department of Civil Engineering, Faculty of Engineering, Chulalongkorn University, Bangkok, THAILAND \\ 254 Phayathai Road, Wangmai, Pathumwan, Bangkok \\ ${ }^{*}$ Corresponding authors: tantri.n.h@ugm.ac.id
}

SUBMITTED 30 July 2021 REVISED 16 September 2021 ACCEPTED 4 October 2021

\begin{abstract}
The tremendous quantity of waste produced from construction and demolition is a major cause of environmental degradation. This quantity tends to increase due to the rapid growth of building development and renovation. Meanwhile, construction waste management is a complex and costly process due to the fact that it requires different kinds of resources such as money, land, and technology. It is often ignored by all project participants even though it is an essential element of construction project management. However, it has been discovered that modern construction waste management is structured based on the concept of circular economy which focuses on eliminating construction waste and maximizing the value of materials. Therefore, this research proposes an innovative framework to implement the circular economy using building information modeling (BIM) in order to improve the construction waste management process. This involved a thorough review of past literature to identify the implementation of the concept of circular economy, waste management, and the application of BIM, also the research gaps observed were used to develop the functionality of the proposed framework. The five functionalities include (1) visualization and data integration, (2) direct construction waste quantity take-off, (3) BIMbased sorting system and selection of appropriate disposal parties, (4) estimating cost and schedule of waste disposal, and (5) simulation and monitoring report. This BIM system was designed to analyze material waste, quantity, disposal time, and waste treatment based on project conditions, material quantities, and schedule. It can also be used to plan and monitor the construction waste process, thereby making it possible to avoid the disruption of productivity and project time usually caused by unplanned waste management activities. Moreover, the proposed on-site sorting system also has the ability to facilitate the adoption of the circular economy concept during the construction phase.
\end{abstract}

KEYWORDS BIM-Based System; Waste Management Planning; Construction Project Management; Circular Economy; Quantity Takeoff; Construction Materials Recycle.

(c) The Author(s) 2022. This article is distributed under a Creative Commons Attribution-ShareAlike 4.0 International license.

\section{INTRODUCTION}

The construction industry is growing rapidly worldwide and also serves as a pillar of the global economy. However, it was discovered to be contributing a significant amount of waste, thereby causing environmental degradation. These construction wastes are associated with the solid waste generated from construction and demolition projects such as concrete, wood products, drywall and plasters, steel, brick and clay tile, asphalt shingles, and asphalt concrete (EPA, 2020). In 2018, a total of 600 million tons of these wastes was generated in the US (EPA, 2020) while 67.8 million tons in the UK (DEFRA, 2021). These numbers reflect the urgency to manage waste accordingly due to the fact that the use of landfills has been discovered to be causing subsequent problems such as social impacts and environmental degradation.

The circular economy is a modern concept designed to minimize the impact of operations on the environment. It was used to transform the traditional linear economy which involves "make, use, and dispose" to a new paradigm that minimizes input, waste, emission, and energy leakage by keeping a product in use for as long as possible and recreating new resources at the end of its service life (Geissdoerfer et al., 2017). The concept is mainly associated with the 3R principles of reduce, reuse, and recycle to 
achieve a more sustainable economy (Anastasiades et al., 2020). Several attempts have been made to develop reused materials such as brick materials (Fořt and Černý, 2020) and sewage sludge ash (Smol et al., 2015a). Moreover, circular economy in construction is associated with technical solutions, user behavior and ownership, bio-based construction, and circularity assessments (Anastasiades et al., 2020). Meanwhile, the efficiency of the design, assembling the reused materials, and minimization of waste have been investigated to support the technical solution aspect. Another potential implementation of circular economy in construction is to improve waste management by changing the current strategies, which are focused on the management after generation, to the aspect related to the prevention (Ajayi et al., 2015). This process requires estimating the amount of waste, scheduling its disposal, quantifying its cost, and collaborating with the parties with the ability to recycle the waste materials. However, there is a need to apply digital technology to ensure the waste management plan is efficiently implemented without expanding the scope of work during the pre-construction process.

Building Information Modeling (BIM) is a virtual representation of building conditions which allows the integration of information to support different aspects of project management throughout the project life cycle. Several BIMbased systems have been proposed to implement a circular economy towards managing construction waste. For example, the disassembly and deconstruction analytics system (D-DAS) introduced to support building design by determining energy costs and waste output indexes (Akanbi et al., 2019). Another is the BIM-based waste management designed to develop waste management plans (Won and Cheng, 2016). However, these systems were discovered to lack coordination and collaboration to support the recycling process.

This research was conducted to thoroughly analyze the current waste management processes and synthesize the findings to develop a BIM-based waste management system with the ability to address the problem more comprehensively. The process involved exploring the potential of BIM to implement the circular economy in construction waste management, analyze the concept based on its implementation in construction projects, as well as evaluate several strategies designed to accelerate its implementation to identify the gaps and potentials. Moreover, the current waste management practices in construction projects were investigated using BIM and the findings were integrated with past literature to establish the framework for a BIM-based circular economy to plan waste management in construction projects by minimizing wastes and maximizing the value of materials.

\section{METHOD OF THE RESEARCH}

A semi-systematic literature review was conducted by gathering relevant literature using designated keywords such as circular economy, waste management, and BIM. The state-of-theart issues from these researches were examined and categorized into three main groups which are circular economy in construction, current construction waste practices, and BIM implementation in waste management with each sub-categorized based on the object of the research or project life cycle. Moreover, potential future research works were also investigated. It is important to note that the circular economy group was the point of departure to ensure the implementation of BIM in construction waste management, while the waste management and current BIM implementation groups were the references to develop the functionality of the proposed framework which was further elaborated to fill the research gap.

\section{CIRCULAR ECONOMY IN CONSTRUCTION}

Circular economy challenges the end-of-life concept by ensuring the prolonged use of materials through reuse, reduce, recover, and recycle principles (Kirchherr et al., 2017). It embraces a regenerative and restorative concept to maximize both value and utility of the products, elements, and materials during their 
service life (Geissdoerfer et al., 2017). The concept has been discovered to be enabling economic growth as indicated by its implementation in several countries. Nevertheless, the implementation process requires certain changes and innovations associated with systems, policies, and organizations.

The actualization of the circular economy is being resisted by some individuals and more severely at the industrial level (Adams et al., 2017). This is observed to be related to the limited knowledge regarding its adoption and the lack of incentive to accelerate the process. Moreover, there is limited discussion on the universal measurement model for the circular economy transition which makes it impossible to track the progress of the implementation process (Jones and Comfort, 2018). These issues persist despite the possibility of using the concept in five important phases including the design, production of materials, construction, maintenance, and the end-of-life (Núñez-Cacho et al., 2018).

There is a need for a paradigm shift from the traditional "linear" design to a "circular" economy through the selection of a suitable project delivery system involving several concepts such as green-field construction, adaptive reuse, and closed-loop cycle construction (Sanchez and Haas, 2018). Therefore, an innovative procurement system was proposed which involves adopting a relational type of contract associated with winning the trust of different parties in order to stem emerging problems through sustainable development of circular economy (Bao et al., 2019). It was also argued that the use of a design tool such as BIM can be a solution in terms of the design (Hossain et al., 2020; Núñez-Cacho et al., 2018).

Defining the supply chain method to be used during the construction phase is essential in designing a circular material supply chain which involves transportation of reused materials and production of lower carbon emission (Nasi et al.,
2017). Another research proposed a strategy to design a waste minimization method during the pre-construction phase by prioritizing recovery strategies over landfilling (Ruiz et al., 2020). Ginga et al. (2020) also showed similar findings which promote eliminating construction wastes observed to be threatening the environment. Meanwhile, ineffective waste deconstruction, sorting, and transportation are the main parts of the waste management practices considered to present the most crucial barrier to the adoption of a circular economy (Mahpour, 2018). These problems were addressed in this current research by proposing a functionality framework which focuses on waste management. The scope of the proposed framework encompasses waste treatment and collaboration among the relevant parties to expand the strategies required to implement the 3R principle.

Several researches on the circular economy focused on inventing new materials from the wastes to preserve the end-of-life of resources (Smol et al., 2015; Osobajo et al., 2020). Some other initiatives were also developed to reuse materials such as brick wastes as substitutes for Portland cement (Fořt and Černý, 2020) and sewage sludge ash in concretes (Smol et al., 2015). Several materials have also been discovered to have the potential to be reused and recycled such as clay bricks, structural timber, structural steel, and concrete blocks (Iacovidou and Purnell, 2016). However, the process of recycling materials is also faced with some challenges associated with logistics (41\%), cost (29\%), time (12\%), regulations (12\%), and others (6\%) (Ghaffar et al., 2020).

It should be noted that the circular economy can be adopted throughout the project life cycle but this current research focuses primarily on project design in the pre-construction phase as well as the use of BIM technology in planning wastes before the construction process and selecting appropriate stakeholders to be included in the waste management system. Moreover, improving the current practices on circular economy such as the establishment of relevant waste plans is very important and this means 
there is a need to examine the key areas of construction influencing its acceleration (Hossain et al., 2020). The outline of the aforementioned circular economy concept is presented in the following Figure 1.

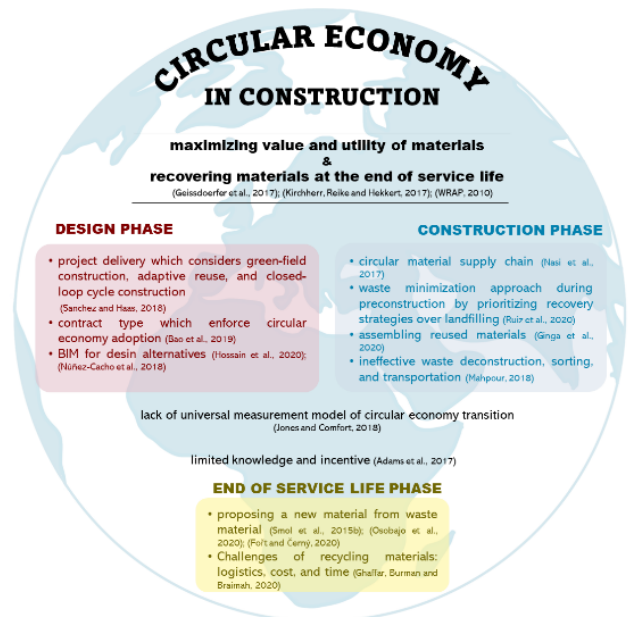

Figure 1. Outline of the circular economy concept in construction

\section{CURRENT CONSTRUCTION WASTE MANAGEMENT PRACTICES}

Demolition is the construction process with the highest quantity of wastes followed by the civil and foundation works (Lu et al., 2015). These processes generate the top three construction material wastes namely concrete, asphalt concrete, and wood products (EPA, 2020). The diversity in the properties of these materials and their waste management practices show there is a need to focus on each of them separately in preparing a waste management plan.

The impact of construction waste is not limited to the environmental pollutions and ecological damage, but also the cost overruns, project delays, economic losses, and social impact (Nagapan et al., 2012). The current management practices are observed to be weakened by lack of regulation, low percentage of on-site waste sorting, poor waste reduction, and the lack of systematic planning such as recycling facilities (Yuan, 2013). Moreover, the previous research correlated waste management with social performances such as public satisfaction, public appeal to regulate dumping waste, new job opportunities, and physical working conditions in addition to its effect on the environmental and project goals (Yuan, 2012).

Most architects do not consider waste minimization strategies during the design phase because the process is placed on a low priority (Osmani, et al. 2008) possibly due to the lack of appropriate policies for its enforcement and the absence of adequate incentives. The contractors also believe an appropriate waste management practice can reduce their profit due to the lack of incentives, practical tools, and guidelines (Papargyropoulou, 2011). This finding contrasts with another research where waste management practices were perceived to be beneficial in terms of cost savings and profit maximization, but the relationship between project characteristics and the benefits was not clarified (Hwang and Yeo, 2011). This simply shows that the perception of waste management systems varies in each case.

A waste management policy can be a supportive tool to achieve success. For example, Hong Kong's waste management policy designed using the 3R and "polluter pays" principles was perceived to be effective in reducing construction waste at landfills ( $\mathrm{Lu}$ and Tam, 2013). Another research showed that the waste disposal charging scheme was perceived to be efficient by only $40 \%$ of the respondents due to the existence of some inevitable wastes and the fact that the cost was not high enough to raise awareness (Poon et al., 2013). It is also possible to support waste minimization through the occasional imposition of penalties for poor waste management parties (Arif et al., 2012).

The waste generation rate is a key performance index of waste management (Lu et al., 2015) and this means that it is necessary to select an appropriate method to estimate the construction waste. This can be achieved based on the quantity of the work which is categorized by the type such as demolition, wreckage, and waste packaging (Solís-Guzmán et al., 2009). The rate can also be influenced by policies, for example, the waste calculation method in Hong Kong was shifted from the gross floor area or total contract sum to the payment of contract sum for each 
work (Poon et al., 2013). This policy provides future opportunities to create an incentive for contractors that submit waste estimation during the tender process (Arif et al., 2012). Therefore, it is necessary to adjust the waste calculation method, document the amount of waste, and monitor the actual waste generated. These features are addressed in this research to develop the framework for the proposed waste management system.

The process of disposing construction wastes varies from one country to another. This is observed from the findings of Hossain, et al. (2017) that the construction waste in Hong Kong is usually generated in the form of mixed wastes to be sorted at both on-site and off-site sorting areas. The non-inert wastes are normally processed to landfills while inert wastes are usually managed using the public fill. Meanwhile, an on-site sorting system was suggested to be adopted due to its effectiveness and ability to reduce environmental impacts. It also has the ability to promptly determine the next step for the recycled materials such as a direct reuse on-site, transportation to the recycled plants for processing, or transportation to landfills and public fill facilities. However, there is a lack of adequate information on the related parties despite the ability of this sorting system to separate the recycled materials effectively. It was also discovered that the wastes are usually moved directly to the landfill (Nagapan et al., 2012) or burnt illegally (Papargyropoulou, 2011) in a situation where there is no waste management or sorting system, thereby endangering the environment. Therefore, these research findings and gaps indicate the need to include waste disposal plan destinations, specify waste carriers, and document recovery actions systematically in the waste management process. This proposition conforms with the findings of Saez et al. (2013) that it is possible to reduce construction waste by recruiting suppliers specialized in managing waste products and planning the sizes of the containers to match the construction activities. It is important to note that these aspects were also considered in the development of the proposed framework.

Several innovative tools and technologies have been adopted to support the waste management process and these include the Waste Management Plan template and Designing Out Waste Tool Building which incorporate plans, outputs, and costs (WRAP, 2010). A similar tool, SMARTWaste, (BRE, 2021) was also developed to estimate the construction wastes to be generated but these technologies are limited by the lack of collaboration between related parties and the flexibility of waste calculation methods. The adoption of BIM is believed to have the ability to create a framework to address the current problems observed in waste management (Osmani and Villoria-Sáez, 2019). Therefore, a BIM-based framework was developed in this current research to address these problems systematically and efficiently.

\section{BIM IMPLEMENTATION ON WASTE MANAGEMENT AND CIRCULAR ECONOMY}

BIM has been verified to have the ability to support waste management through design review, 3D coordination, quantity take-off, phase planning, site utilization planning, construction system design, digital fabrication, and 3D control and planning (Won and Cheng, 2017). It also accommodates the requirements of the stakeholders in its implementation and strengthens several features such as collaboration, waste-driven design, waste analysis during the whole project lifecycle, innovative analysis, and systematic documentation in the waste management process (Akinade et al., 2018).

A BIM-Deconstructability Assessment Score (BIM-DAS) was proposed to assist the designer in selecting the best design among possible alternatives via an assessment score which considers the reusability, recyclability and secondary finishes, as well as the toxicity of the materials (Akinade et al., 2015). This system can also simulate design alternatives and their assessment scores. Moreover, another waste management tool was proposed to accommodate 
both design options and construction schemes through the automatic estimation of the wastes in each scenario considering the fact that the waste generated waste cannot be incorporated into the design (Lu et al., 2017). Therefore, the waste generation was calculated by mapping the component on the database of the average waste generation level. Another research also showed the ability of BIM to support the design process with a specific focus on the processes involved in assembling and dissembling a building which consists of collaboration, visualization of deconstruction, quantification of recoverable materials, deconstruction plan, simulating endof-life alternatives, and improving building lifecycle (Akinade et al., 2017). It can be discovered that several BIM-based systems have been used to select, simulate, and optimize design alternatives, but they are not designed specifically to support waste management.

Several BIM-based systems are integrated into database systems such as the material \& component bank which stores materials and components for basic waste management in order to ensure the efficiency of the systems (Jayasinghe and Waldmann, 2020). This concept was also adopted in this research to manage nongeometric information due to the fact that the 3D models primarily focus on geometrical information.

BIM is an efficient tool to perform quantity takeoff of construction materials and can also be extended to the estimation of waste quantity. A BIM-based system was reported to have been used to estimate the wastes during the design review through clash detection and constructability review (Won et al., 2016). This was conducted using a work breakdown structure provided in the BIM-based software and material classification standards (Kim et al., 2017). Moreover, the accuracy of the process was enhanced through the integration of a linear BIM-based quantity take-off into the material purchasing database (Guerra et al., 2019). It was observed that there was a lack of collaboration between the disposal parties and this is expected to be addressed through the proposed system which was designed to estimate the amount of waste generated and the waste disposal charging fee based on the waste facilities available (Cheng and Ma, 2013). These findings were adopted in this current research to develop an extensive monitoring system for waste disposal practices.

This means the BIM has the capability to ensure the prolonged use of materials at the end of their service life. Previous research also showed that As-built BIM models can be used to develop a demolition plan in line with the preferred method and waste identification system (Ge et $a l ., 2017)$. They also serve as the tool to perform a cost-benefit analysis for demolition waste management (Hamidi et al., 2014) even when the details of the framework have not been developed. However, the current framework of BIM implemented is based on local policies (Akbarieh et al., 2020) without global coverage. Therefore, the proposed framework was designed to be flexible to ensure it can be easily implemented in any organization or country.

\section{FUNCTIONALITY OF THE PROPOSED FRAMEWORK}

The proposed framework is primarily designed to manage waste during construction with a focus on the quantity of waste, time of disposal, cost, as well as disposal parties and places. This is based on the fact that the integration of the BIM has the ability to plan waste management during the pre-construction phase and also to monitor the waste management process during the construction phase. The visualization of the BIM-based system allows the thorough understanding of the site conditions while the data integration system has the ability to create a systematic workflow, provide a high level of calculation accuracy, and support mutual collaboration works. Moreover, the use of quantity take-off by BIM leads to accurate waste estimates. The development of the framework functionality is presented in Figure 2.

Some of the uses of BIM in waste management include 4D simulation, quantity take-off, design review, 3D coordination, and site utilization planning (Won and Cheng, 2017). The proposed 
framework only adopted the 4D simulation and quantity take-off to achieve the research objectives, but it is possible to extend these functionalities to a BIM-based platform in order to ensure its actual implementation. Therefore, the features of the proposed BIM-based framework are presented in the following Figure 3.

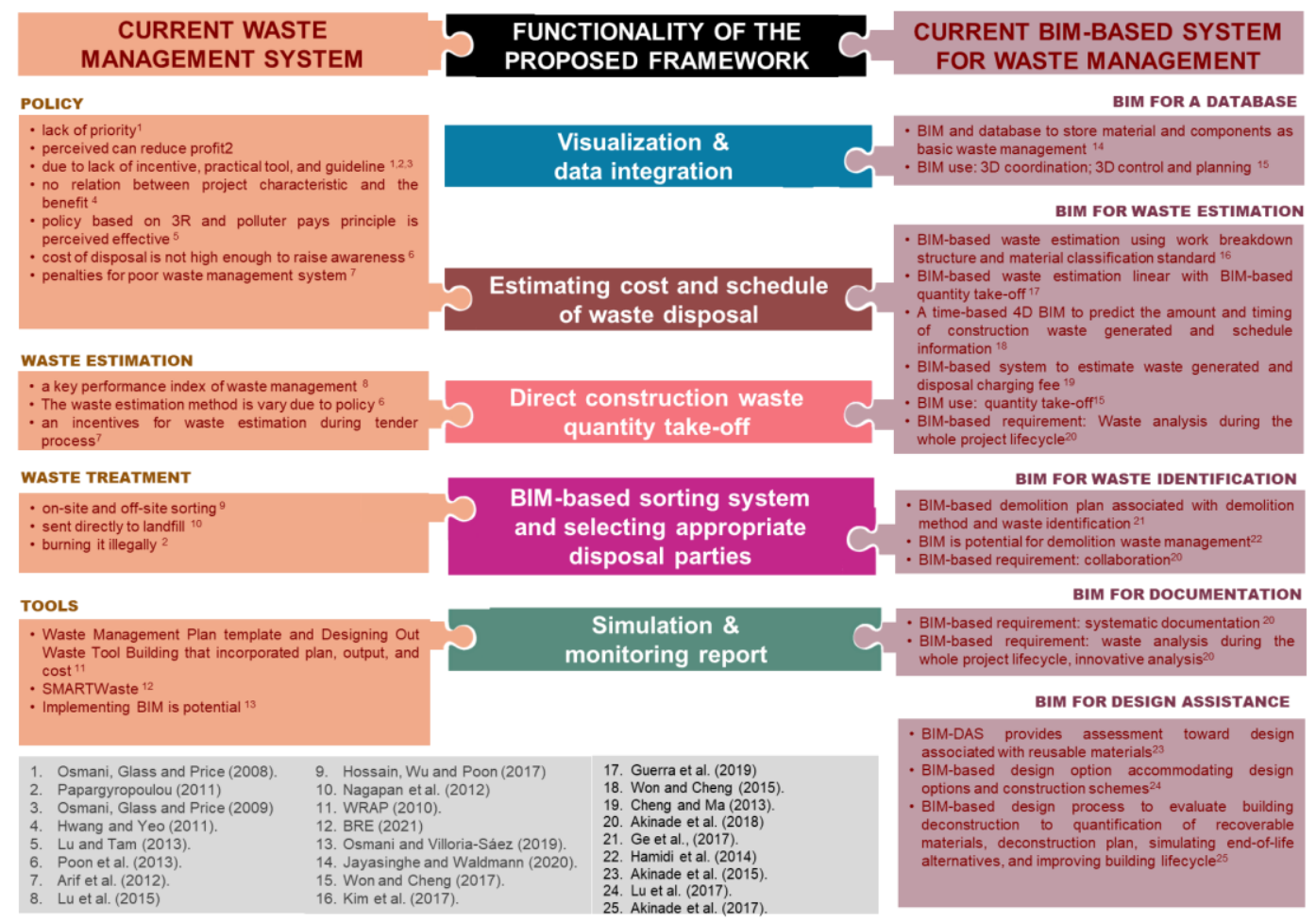

Figure 2. Research gaps and the proposed framework

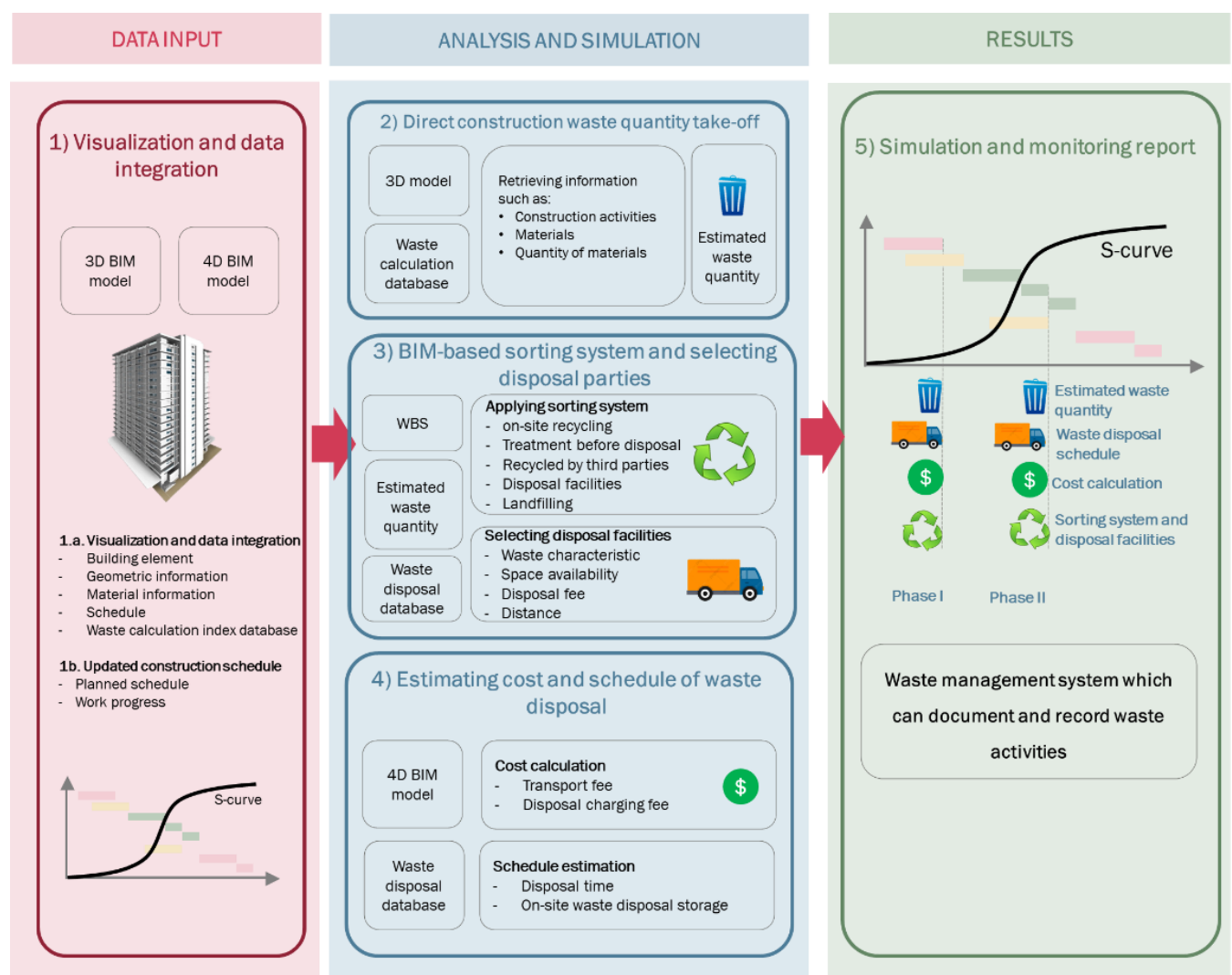

Figure 3. The functionality of the proposed framework 


\subsection{Visualization and data integration}

The proposed system involves a 3D BIM model which was used as the central database consisting of the geometric information of the building elements such as the identity, size, shape, length, and material of each element. It is important to note that the BIM model has the same level of detail (LOD) as required in the construction phase to obtain an accurate estimate for the wastes. Moreover, the model includes every permanent part of the building elements in order to clearly present the actual building conditions.

The BIM model also contains important nongeometric information necessary for further analyses such as cost, schedule, and the database of disposal parties which are integrated by analyzing the work breakdown structure (WBS) of the model. The correlations between the nongeometric information and the building elements were later identified and represented by codes. It is important to note that the scope of the data integration encompasses the waste generation indexes to estimate the waste, schedule information, the sorting system for each material, and the disposal parties. Several methods have been proposed to integrate the geometric and non-geometric information and some of these include using the element ID and Dynamo program (Handayani et al., 2019) and the WBS (Kang et al., 2010). However, the ability of the model to simulate design alternatives using parametric modeling in order to determine the design with the minimum waste (Hang et al., 2021; Likhitruangsilp et al., 2019) was not included in this research.

\subsection{Direct construction waste quantity take-off}

Previous discussions showed the need for the system to be adjustable to different waste estimation methods due to the fact that the process of estimating waste is based on the amount of construction works conducted. This was achieved in the proposed system by extracting the quantity of the material from the 3D model along with the associated information. The data and information extracted are expected to be user-friendly in order to facilitate the appropriate exchange of information and waste estimation. Moreover, the 3D model was observed to have yielded accurate estimation results and this can be applied to place orders for materials during the construction phase. This simply shows that the BIM model is adjustable to the change in the site condition during the construction process.

It is recommended that further research needs to be conducted to incorporate the waste estimation method as well as an integrated database for storing the parameters such as waste estimation indexes into the system. It is also advisable to organize the database based on materials, modular and non-modular types, and types of waste generated in order to automate the process and ensure it requires fewer inputs from the users. In addition, the system can also be extended through the addition of features relating to waste minimization for modular materials by optimizing construction methods and simulating alternative installment scenarios.

\subsection{BIM-based sorting system and selecting appropriate disposal parties}

The structure of the BIM-based sorting system module was based on the work breakdown structure (WBS) which consists of different activities involved in the construction, materials, and waste generated. The system was further sub-categorized into inert and non-inert waste, potential on-site recycling materials, potential recycling by third parties, public disposal facilities, free or non-free disposal facilities, and landfills. This hierarchical structure represents the $3 \mathrm{R}$ principle which is in line with the concept of circular economy formulated to minimize environmental degradation.

Most of the current waste management systems focus on estimating wastes and the disposal system was observed to be directly related to the design of construction waste management as previously discussed. However, these disposal methods need to be evaluated to determine whether the construction waste materials are causing environmental degradation or ensuring 
the end-of-life of materials is prolonged in order to support the circular economy concept. This can be achieved by using the data integration system which allows the connection of each waste generated to disposal parties and also makes it possible for the sorting system to select the appropriate disposal facilities or recycling parties based on several parameters such as the waste characteristics, space availability, disposal/recycling fees, and distance. These outcomes aided the linkage of the disposed wastes to appropriate parties in order to minimize emissions usually caused by transportation.

\subsection{Estimating cost and schedule of waste disposal}

The main results of integrating geometric and non-geometric data are 4D and 5D BIM models which allow the estimation of the waste quantity based on the values derived from the BIM model and waste calculation database. The estimates were used to determine the associated costs such as disposal charging fees and transportation costs which are usually obtained based on the sorting system and the selected disposal parties.

The 4D BIM model in the proposed system is required to be regularly updated in order to reflect the construction progress and actual schedule. This information and the estimated quantity of waste usually provide the contractor with an early warning concerning the disposal schedule. The proposed system also optimizes the time of waste disposal by considering the onsite storage and this allows the contractor to plan the resources to be used in managing wastes. Meanwhile, the possibility of preparing this estimation before the construction process is initiated makes it constructive for the contractor to submit the bidding documents with a detailed waste management plan.

\subsection{Simulation and monitoring report}

The waste management plan prepared before the construction process can be used as a guideline during the construction. This is possible because the BIM-based system can be updated to reflect the change in the schedule information and construction conditions. Moreover, it is necessary to record the quantity of wastes and the result of the sorting system, method of disposal, as well as the correlation of cost and time for each waste disposal activity. This is necessary to ensure that there is a systematic record of waste disposal activities for the project and which can be used later for further analyses.

\section{CONCLUSION}

This research was conducted to investigate the implementation of circular economy in the construction industry through the maximization of the construction materials value and recovery of these materials at the end of their service life. The major challenges observed with this concept include the lack of a universal measurement for the circular economy transition as well as limited knowledge and incentive. However, managing wastes and reusing construction materials were reported to have a major role in promoting circular economy in construction, but they were observed to be from perfect due to a lack of incentives, practical tools, and guidelines for waste quantification. Therefore, BIM is considered a potential innovation to improve the management process and this research examined the efficiency of its application in waste management.

The formulation of waste management plans involves estimating the quantity of waste, documenting waste disposal activities, and selecting the appropriate waste disposal alternatives with the ability to prolong the endof-life of materials in order to achieve the goals of the circular economy concept. The gaps observed in the findings of these previous researches were synthesized with the BIM to develop a framework system for the circular economy. The functionality of this proposed BIM-based waste management system consists of five modules, namely: (1) visualization and data integration, (2) direct determination of construction waste quantity take-off, (3) BIMbased sorting system and selection of appropriate disposal parties, (4) estimation of cost and schedule of waste disposal, and (5) 
simulation and preparation of monitoring report.

The visualization module used the BIM to represent the conditions of the facility effectively while the data integration concept was introduced to manage the geometric and non-geometric information of the facility. Moreover, the BIM was also used to estimate the waste and associated costs due to its ability to quantify materials accurately while the waste disposal schedule was established through the 4D BIM. It is also important to note that the work breakdown structure (WBS) in the BIM allowed the classification of the wastes to be disposed into suitable parties. Furthermore, the system has the ability to record and document waste activities based on the associated costs, schedule, and associated parties during the construction phase.

There are certain limitations observed with this proposed framework despite its numerous benefits in achieving the circular economy concept in construction. Therefore, additional functions such as information exchanges, platforms, and supporting tools are required to be developed further. It is also necessary to verify the reliability of the waste calculation by the system and to improve the flexibility of the proposed framework in adopting the organization code related to waste management. Moreover, the level of work breakdown structure needs to be evaluated to integrate the $4 \mathrm{D}$ and $5 \mathrm{D}$ BIM models and also to develop an appropriate BIM-based sorting system. The scope of the proposed waste management system can also be extended by considering the design and construction alternatives in order to minimize wastes. Furthermore, it is recommended that the proposed system be tested with a case research after it has been fully developed.

\section{DISCLAIMER}

The authors declare no conflict of interest.

\section{AVAILABILITY OF DATA AND MATERIALS}

All data are available from the author

\section{AUTHOR CONTRIBUTION STATEMENTS}

Tantri N. H conceived the idea and designed the analysis. Kartika N. R. P analyzed the literature regarding BIM, Nurul A. I. improving the topic on waste management, and Veerasak L. contributed on circular economy concept. All authors took a substantial contribution in developing the framework, discussing the result, and drafting the manuscript

\section{ACKNOWLEDGMENTS}

The author appreciates the Civil and Environmental Engineering Department, Universitas Gadjah Mada for funding this research.

\section{REFERENCES}

Adams, K.T., Osmani, M., Thorpe, T. and Thornback, J., 2017. Circular economy in construction: current awareness, challenges and enablers. Proceedings of Institution of Civil Engineers: Waste and Resource Management, 170(WR1), pp.15-24.

Ajayi, S.O., Oyedele, L.O., Bilal, M., Akinade, O.O., Alaka, H.A., Owolabi, H.A. and Kadiri, K.O., 2015. Waste effectiveness of the construction industry: Understanding the impediments and requisites for improvements. Resources, Conservation and Recycling, 102, pp.101-112.

Akanbi, L.A., Oyedele, L.O., Omoteso, K., Bilal, M., Akinade, O.O., Ajayi, A.O., Davila Delgado, J.M. and Owolabi, H.A., 2019. Disassembly and deconstruction analytics system (D-DAS) for construction in a circular economy. Journal of Cleaner Production, 223, pp.386-396.

Akbarieh, A., Jayasinghe, L.B., Waldmann, D. and Teferle, F.N., 2020. BIM-based end-of-lifecycle decision making and digital deconstruction: Literature review. Sustainability (Switzerland), 12(7).

Akinade, O.O., Oyedele, L.O., Ajayi, S.O., Bilal, M., Alaka, H.A., Owolabi, H.A. and Arawomo, O.O., 2018. Designing out construction waste using BIM technology: Stakeholders' expectations for industry deployment. Journal of 
Cleaner Production, 180, pp.375-385.

Akinade, O.O., Oyedele, L.O., Bilal, M., Ajayi, S.O., Owolabi, H.A., Alaka, H.A. and Bello, S.A., 2015. Waste minimisation through deconstruction: A BIM based Deconstructability Assessment Score (BIM-DAS). Resources, Conservation and Recycling, 105, pp.167-176.

Akinade, O.O., Oyedele, L.O., Omoteso, K., Ajayi, S.O., Bilal, M., Owolabi, H.A., Alaka, H.A., Ayris, L. and Henry Looney, J., 2017. BIM-based deconstruction tool: Towards essential functionalities. International Journal of Sustainable Built Environment, 6(1), pp.260-271.

Anastasiades, K., Blom, J., Buyle, M. and Audenaert, A., 2020. Translating the circular economy to bridge construction: Lessons learnt from a critical literature review. Renewable and Sustainable Energy Reviews, 117, pp.1-11.

Arif, M., Bendi, D., Toma-Sabbagh, T. and Sutrisna, M., 2012. Construction waste management in India: An exploratory research. Construction Innovation, 12(2), pp.133-155.

Bao, Z., Lu, W., Chi, B., Yuan, H. and Hao, J., 2019. Procurement innovation for a circular economy of construction and demolition waste: Lessons learnt from Suzhou, China. Waste Management, 99, pp.12-21.

BRE, 2021. SmartWaste -Environmental site monitoring and reporting software. [Online] Available at: https://www.bresmartsite.com/products/smartw aste/ [Accessed 26 July 2021]

Cheng, J.C.P. and Ma, L.Y.H., 2013. A BIM-based system for demolition and renovation waste estimation and planning. Waste Management, 33(6), pp.1539-1551.

DEFRA, 2021. UK Statistics on Waste. [Online] Available at: <https://www.gov.uk/government/statistics/ukwaste-data>. [Accessed 22 July 2021]

EPA, 2020. Advancing Sustainable Materials Management. Washington, DC. [online] Available at: $\quad$ <https://www.epa.gov/facts-and-figuresabout-materials-waste-andrecycling/advancing-sustainable-materialsmanagement>. [Accessed 22 July 2021]

Fořt, J. and Černý, R., 2020. Transition to circular economy in the construction industry: Environmental aspects of waste brick recycling scenarios. Waste Management, 118, pp.510-520.

Ge, X.J., Livesey, P., Wang, J., Huang, S., He, X. and Zhang, C., 2017. Deconstruction waste management through 3D reconstruction and BIM: a case research. Visualization in Engineering, $5(1)$.

Geissdoerfer, M., Savaget, P., Bocken, N.M.P. and Hultink, E.J., 2017. The Circular Economy - A new sustainability paradigm? Journal of Cleaner Production, 143, pp.757-768.

Ghaffar, S.H., Burman, M. and Braimah, N., 2020. Pathways to circular construction: An integrated management of construction and demolition waste for resource recovery. Journal of Cleaner Production, [online] 244, p.118710.

Ginga, C.P., Ongpeng, J.M.C. and Daly, M.K.M., 2020. Circular economy on construction and demolition waste: A literature review on material recovery and production. Materials, 13(13), pp.1-18.

Guerra, B.C., Bakchan, A., Leite, F. and Faust, K.M., 2019. BIM-based automated construction waste estimation algorithms: Waste Management, 87, pp.825-832.

Hamidi, B., Tanyel, B., Annie, P. and Walid, T., 2014. Potential Application of BIM in Costbenefit Analysis of Demolition Waste Management. In: Construction Research Congress 2014. pp.279-288.

Handayani, T.N., Likhitruangsilp, V. and Yabuki, N., 2019. A building information modeling (BIM)-integrated system for evaluating the impact of change orders. Engineering Journal, 23(4), pp.67-90.

Hang, T.T.L., Likhitruangsilp, V. and Yabuki, N., 
2020. A BIM-integrated relational database management system for evaluating building lifecycle costs. Engineering Journal, 24(2), pp.75-86.

Hossain, M.U., Ng, S.T., Antwi-Afari, P. and Amor, B., 2020. Circular economy and the construction industry: Existing trends, challenges and prospective framework for sustainable construction. Renewable and Sustainable Energy Reviews, 130, p.109948.

Hossain, M.U., Wu, Z. and Poon, C.S., 2017. Comparative environmental evaluation of construction waste management through different waste sorting systems in Hong Kong. Waste Management, 69, pp.325-335.

Hwang, B.G. and Yeo, Z.B., 2011. Perception on benefits of construction waste management in the Singapore construction industry. Engineering, Construction and Architectural Management, 18(4), pp.394-406.

Iacovidou, E. and Purnell, P., 2016. Mining the physical infrastructure: Opportunities, barriers and interventions in promoting structural components reuse. Science of the Total Environment, 557-558, pp.791-807.

Jayasinghe, L.B. and Waldmann, D., 2020. Development of a BIM-based web tool as a material and component bank for a sustainable construction industry. Sustainability (Switzerland), 12(5), pp.1-15.

Jones, P. and Comfort, D., 2018. The Construction Industry and the Economy. International Journal of Management Cases, 20(1), pp.4-15.

Kang, L.S., Moon, H.S., Park, S.Y., Kim, C.H. and Lee, T.S., 2010. Improved link system between schedule data and 3D object in 4D CAD system by using WBS code. KSCE Journal of Civil Engineering, 14(6), pp.803-814.

Kim, Y.C., Hong, W.H., Park, J.W. and Cha, G.W., 2017. An estimation framework for Building Information Modeling (BIM)-based demolition waste by type. Waste Management and Research, 35(12), pp.1285-1295.
Kirchherr, J., Reike, D. and Hekkert, M., 2017. Conceptualizing the circular economy: An analysis of 114 definitions. Resources, Conservation and Recycling, 127, pp.221-232.

López Ruiz, L.A., Roca Ramón, X. and Gassó Domingo, S., 2020. The circular economy in the construction and demolition waste sector - A review and an integrative model approach. Journal of Cleaner Production, 248.

Likhitruangsilp, V., Le, H.T.T., and Yabuki, N., 2019. Integrating Building Information Modeling and Visual Programming for Building Life-Cycle Cost Anaylsis. Proc. of the Tenth International Structural Engineering and Construction Conference (ISEC 2019), Chicago, Illinois, US, May 20-25, 2019.

Lu, W., Chen, X., Peng, Y. and Shen, L., 2015. Benchmarking construction waste management performance using big data. Resources, Conservation and Recycling, 105, pp.49-58.

Lu, W. and Tam, V.W.Y., 2013. Construction waste management policies and their effectiveness in Hong Kong: A longitudinal review. Renewable and Sustainable Energy Reviews, 23, pp.214-223.

Lu, W., Webster, C., Chen, K., Zhang, X. and Chen, X., 2017. Computational Building Information Modelling for construction waste management: Moving from rhetoric to reality. Renewable and Sustainable Energy Reviews, 68, pp.587-595.

Mahpour, A., 2018. Prioritizing barriers to adopt circular economy in construction and demolition waste management. Resources, Conservation and Recycling, 134, pp.216-227.

Nagapan, S., Rahman, I.A., Asmi, A., Memon, A.H. and Latif, I., 2012. Issues on construction waste: The need for sustainable waste management. CHUSER 2012 - 2012 IEEE Colloquium on Humanities, Science and Engineering Research, pp.325-330.

Nasi, M., Genovese, A., Acquaye, A.A., Koh, S.C.L. and Yamoah, F., 2017. A comparison 
between linear and circular supply chains: a case research from the construction industry. International Journal of Production Economics, 183, Part B: 443-457.

Núñez-Cacho, P., Górecki, J., Molina, V. and Corpas-Iglesias, F.A., 2018. New Measures of Circular Economy Thinking In Construction Companies. Journal of EU Research in Business, 2018, pp.1-16.

Osmani, M., Glass, J. and Price, A.D.F., 2008. Architects' perspectives on construction waste reduction by design. Waste Management, 28(7), pp.1147-1158.

Osmani, M. and Villoria-Sáez, P., 2019. Current and Emerging Construction Waste Management Status, Trends and Approaches. Waste, pp.365380.

Osobajo, O.A., Oke, A., Omotayo, T. and Obi, L.I., 2020. A systematic review of circular economy research in the construction industry. Smart and Sustainable Built Environment, 260, p.121046.

Papargyropoulou, E., 2011. Sustainable construction waste management in Malaysia: a constructor's perspective. Proceeding of Management and Innovation for a Sustainable Built Environment.

Poon, C.S., Yu, A.T.W., Wong, A. and Yip, R., 2013. Quantifying the Impact of Construction Waste Charging Scheme on Construction Waste Management in Hong Kong. Journal of Construction Engineering and Management, 139(5), pp.466-479.

Saez, P.V., Del Río Merino, M., San-Antonio González, A. and Porras-Amores, C., 2013. Best practice measures assessment for construction and demolition waste management in building constructions. Resources, Conservation and
Recycling, 75, pp.52-62.

Sanchez, B. and Haas, C., 2018. Capital project planning for a circular economy. Construction Management and Economics, 36(6), pp.303-312.

Smol, M., Kulczycka, J., Henclik, A., Gorazda, K. and Wzorek, Z., 2015a. The possible use of sewage sludge ash (SSA) in the construction industry as a way towards a circular economy. Journal of Cleaner Production, 95, pp.45-54.

Solís-Guzmán, J., Marrero, M., Montes-Delgado, M.V. and Ramírez-de-Arellano, A., 2009. A Spanish model for quantification and management of construction waste. Waste Management, 29(9), pp.2542-2548.

Won, J. and Cheng, J.C.P., 2017. Identifying potential opportunities of building information modeling for construction and demolition waste management and minimization. Automation in Construction, 79, pp.3-18.

Won, J., Cheng, J.C.P. and Lee, G., 2016. Quantification of construction waste prevented by BIM-based design validation: Case researches in South Korea. Waste Management, 49, pp. 170-180.

WRAP, 2010. Designing out Waste Tool for Buildings. [online] Designing out Waste Tool for Buildings, Quick Start Guide, Version 1.0, Available at: <http://dowtb.wrap.org.uk/>. [Accessed 22 July 2021]

Yuan, H., 2012. A model for evaluating the social performance of construction waste management. Waste Management, 32(6), pp.1218-1228.

Yuan, H., 2013. A SWOT analysis of successful construction waste management. Journal of Cleaner Production, 39, pp.1-8. 
[This page is intentionally left blank] 